\title{
Dosimetric properties of $\mathrm{Tb}$-doped $\mathrm{LiF} / \mathrm{CaF}_{2}$ eutectic composite
}

\author{
Noriaki KAWAGUCHI ${ }^{1} \uparrow$, Hiromi KIMURA ${ }^{1}$, Daisuke NAKAUCHI ${ }^{1}$, \\ Takumi KATO ${ }^{1}$ and Takayuki YANAGIDA ${ }^{1}$ \\ ${ }^{1}$ Nara Institute of Science and Technology, 8916-5 Takayama, Ikoma, Nara 630-0192, Japan
}

We have developed a $\mathrm{LiF} / \mathrm{CaF}_{2}$ : $\mathrm{Tb}$ eutectic composite as a novel thermoluminescence (TL) dosimetric material. The $\mathrm{LiF} / \mathrm{CaF}_{2}$ : Tb eutectic composite was obtained using a melt-solidification method with a lower melting temperature than that of $\mathrm{LiF}$ and $\mathrm{CaF}_{2}$. The results of the PL emission and excitation spectra, the $\mathrm{X}$-ray induced radioluminescence decay curve, and the $\mathrm{TL}$ emission spectrum indicate that the emissions of $\mathrm{LiF} / \mathrm{CaF}{ }_{2}: \mathrm{Tb}_{\mathrm{eutec}}$ tic composite are due to $4 \mathrm{f}-4 \mathrm{f}$ transitions of the $\mathrm{Tb}^{3+}$ ion. The integrated $\mathrm{TL}$ intensity of the $\mathrm{LiF} / \mathrm{CaF}_{2}: \mathrm{Tb}_{\mathrm{eutectic}}$

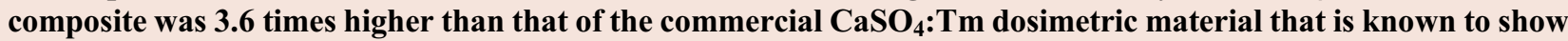
a relatively high TL intensity. The dose response curve of the $\mathrm{LiF} / \mathrm{CaF}_{2}: \mathrm{Tb}$ eutectic composite was measured and the lower detection limit was $0.01 \mathrm{mGy}$ which is the lowest value among the $\mathrm{LiF} / \mathrm{CaF}_{2}$ based composites.

(02021 The Ceramic Society of Japan. All rights reserved.

Key-words : Eutectic, Composite, Fluoride, Dosimetric material

[Received January 5, 2021; Accepted February 5, 2021]

\section{Introduction}

Although various single crystals, sintered ceramics, glasses, and powders have been studied as inorganic phosphor materials, there are few studies on eutectic composites for phosphor applications. Eutectic is a state in which a liquid phase becomes multiple solid phases when an inorganic matter solidifies. In eutectic phase, composite materials with a micrometer sized structure can be obtained. ${ }^{1), 2)}$ In general, eutectic compositions have relatively lower melting points than their similar compositions; therefore, eutectics are expected to be manufactured at low cost. As one of the few examples, $\mathrm{Al}_{2} \mathrm{O}_{3} / \mathrm{Y}_{3} \mathrm{Al}_{5} \mathrm{O}_{12}$ : $\mathrm{Ce}$ eutectics have been studied for a yellow phosphor layer in white LEDs and LDs. ${ }^{3)}$ Since the $\mathrm{Al}_{2} \mathrm{O}_{3} / \mathrm{Y}_{3} \mathrm{Al}_{5} \mathrm{O}_{12}$ eutectic is known as a sufficiently high strength and stable material, ${ }^{4)}$ the $\mathrm{Al}_{2} \mathrm{O}_{3} / \mathrm{Y}_{3} \mathrm{Al}_{5} \mathrm{O}_{12}$ :Ce eutectic can be regarded as a material having both an efficient luminescence property and a high mechanical property. We have also been interested in eutectic composites as neutron scintillators ${ }^{5)-7)}$ that have a function to convert neutrons to photons. A neutron scintillator is combined with a photodetector and used for a neutron detector. ${ }^{8)}$ We have studied $\mathrm{LiF} / \mathrm{CaF}_{2}$ : $\mathrm{Ce}$ and $\mathrm{LiF} / \mathrm{CaF}_{2}: \mathrm{Eu}$ eutectics as neutron scintillators. In particular, the $\mathrm{LiF} / \mathrm{CaF}_{2}: \mathrm{Eu}$ eutectic shows a high light yield and neutron detection efficiency. ${ }^{9), 10)}$ Its performance is comparable to those of other fluoride single crystals. ${ }^{11)}$

Corresponding author: N. Kawaguchi; E-mail:n-kawaguchi@ ms.naist.jp

¥ Preface for this article: Dol http://doi.org/10.2109/jcersj2. 129.P7-1
These studies are the examples of eutectic composites for phosphor applications.

In recent years, we are focusing on eutectic composites for dosimeter applications. Dosimeters have a function to measure radiation dose during certain terms and phosphortype dosimeters are mainly used. Such phosphors applied for dosimeters can be classified as the following three types: thermoluminescence (TL), ${ }^{12)}$ optically-stimulated luminescence, ${ }^{13)-15)}$ and radio-photoluminescence ${ }^{16)-18}$ ) dosimetric materials. Since their luminescence intensities monotonically increase with increasing radiation doses, these phosphors can be applied for radiation dosimetry. Among them, TL dosimetric materials are the most traditional and widely studied material. As the TL dosimetric materials, for example, $\mathrm{LiF}: \mathrm{Mg}, \mathrm{Ti}, \mathrm{LiF}: \mathrm{Mg}, \mathrm{Cu}, \mathrm{P}, \mathrm{Mg}_{2} \mathrm{SiO}_{4}$ : $\mathrm{Tb}$, and $\mathrm{CaSO}_{4}: \mathrm{Tm}$ are known. ${ }^{19)}$ Such TL dosimetric materials are mainly sintered ceramics or inorganic powder composites with an organic matrix. On the other hand, we have reported $\mathrm{TL}$ dosimetric properties of $\mathrm{LiF} / \mathrm{CaF}_{2}: \mathrm{Ce},{ }^{20}$ ) $\mathrm{LiF} / \mathrm{CaF}_{2}: \mathrm{Eu}^{21)}$ and non-doped $\mathrm{LiF} / \mathrm{CaF}_{2}{ }^{22)}$ eutectic composites. These eutectics are the rare reported examples of inorganic-inorganic composites as TL dosimetric materials. We have shown that $\mathrm{LiF} / \mathrm{CaF}_{2}: \mathrm{Ce}, \mathrm{LiF} / \mathrm{CaF}_{2}: \mathrm{Eu}$, and non-doped $\mathrm{LiF} / \mathrm{CaF}_{2}$ can act as $\mathrm{TL}$ dosimetric materials and are potentially cost effective, however, their lower detection limits were $0.1-1 \mathrm{mGy}$ that are not sufficient values compared with those of other efficient materials (e.g., $0.01 \mathrm{mGy}$ by the $\mathrm{LiCaAlF}_{6}: \mathrm{Tb}$ single crystal ${ }^{23)}$ ) evaluated by the same measurement setups in our group.

In this study, we have developed $\mathrm{LiF} / \mathrm{CaF}_{2}: \mathrm{Tb}$ as a novel eutectic TL dosimetric material. Because the $\mathrm{Tb}^{3+}$ ions can be used for a luminescent center of TL dosimetric 
materials (e.g., $\mathrm{Mg}_{2} \mathrm{SiO}_{4}: \mathrm{Tb}$ ), we had expected to obtain the more efficient eutectic TL dosimetric material. In order to demonstrate the potential of the eutectic composite as the TL dosimetric material, we have investigated its dosimetric properties comparing with the non-doped LiF/ $\mathrm{CaF}_{2}$ eutectic composite and the commercial material.

\section{Experimental procedure}

The $\mathrm{LiF} / \mathrm{CaF}_{2}: \mathrm{Tb}$ eutectic composite was prepared using a melt-solidification method. The high-purity LiF, $\mathrm{CaF}_{2}$, and $\mathrm{TbF}_{3}$ powders $(99.99 \%$, Stella chemifa) were mixed with a mole ratio at the eutectic point of $\mathrm{LiF}$ and $\mathrm{CaF}_{2}\left(\mathrm{LiF}: \mathrm{CaF}_{2}=79.2: 20.8\right)$ together with $0.1 \mathrm{~mol} \%$ of $\mathrm{TbF}_{3}$ for $\mathrm{CaF}_{2}$. The mixed powders were poured into a carbon crucible and heated to remove water under vacuum $\left(8 \times 10^{-4} \mathrm{~Pa}\right)$ at $500^{\circ} \mathrm{C}$ for $5 \mathrm{~h}$ in a vacuum chamber with a carbon heater and carbon heat insulators. After removing water from the mixed powders, the temperature of the crucible was changed from 500 to $850^{\circ} \mathrm{C}$ at a heating rate of $10^{\circ} \mathrm{C} / \mathrm{min}$ under Ar atmosphere. The temperature was kept at $850^{\circ} \mathrm{C}$ for $30 \mathrm{~min}$ for melting the mixed powders, then it was decreased to $20^{\circ} \mathrm{C}$ at a cooling rate of $4{ }^{\circ} \mathrm{C} / \mathrm{min}$. This temperature profile is the same as that for the non-doped $\mathrm{LiF} / \mathrm{CaF}_{2}$ eutectic composite in the previous report. ${ }^{22)}$ The obtained eutectic is polished to a thickness of approximately $2 \mathrm{~mm}$ and it is used as the sample for investigation on the luminescence and dosimetric properties.

In order to investigate luminescence properties, the photoluminescence (PL) spectra and the X-ray induced radioluminescence decay curve were measured. The PL emission and excitation spectra were measured using a PL spectrometer (FP-8600; JASCO). The PL emission spectrum was measured with $230 \mathrm{~nm}$ excitation wavelength. The PL excitation spectrum was measured with $543 \mathrm{~nm}$ emission wavelength. The X-ray induced radioluminescence decay curve was measured by a time-correlated single photon counting system using a pulse X-ray source and a photomultiplier tube (R7400P-06; Hamamatsu). The detail is described elsewhere. ${ }^{24)}$ In this experiment, the $\mathrm{X}$-ray tube voltage was set $30 \mathrm{kV}$. The decay time was estimated by fitting the obtained decay curve to a single exponential function.

In order to investigate TL dosimetric properties, the TL emission spectrum and TL glow curves were measured. Before both measurements, the samples were irradiated with certain doses of X-rays using an X-ray generator (XRB80P\&N200X4550; Spellman). The X-ray doses (air kerma) were estimated using an ionization chamber (Model 30013; PTW). The TL emission spectrum was measured in the temperature range from 50 to $300^{\circ} \mathrm{C}$ by a CCD-based spectrometer (QE Pro; Ocean Optics) with heating the sample by a ceramic heater (SCR-SHQ-A; Sakaguchi E.H Voc). The detail of the measurement is shown elsewhere. ${ }^{25}$ ) The TL glow curves were obtained using a TL reader (TL-2000; Nanogray) with a heating rate of $1^{\circ} \mathrm{C} / \mathrm{s}$ from 50 to $400^{\circ} \mathrm{C}$. To obtain the dose response curves, this measurement is repeated under different X-ray doses from 0.1 to $10 \mathrm{mGy}$. The details of this measurement is shown elsewhere. ${ }^{26}$ ) In the TL glow curve measurements, the commercial $\mathrm{CaSO}_{4}: \mathrm{Tm}$ dosimetric material (Panasonic) was used as the reference sample. The reason why $\mathrm{CaSO}_{4}: \mathrm{Tm}$ was selected was that it has relatively high TL intensity among well-known TL dosimetric materials. ${ }^{19)}$ The non-doped $\mathrm{LiF} / \mathrm{CaF}_{2}$ eutectic composite, that had been obtained in the previous study, ${ }^{22)}$ was also used for the reference sample.

\section{Results and discussion}

The $\mathrm{LiF} / \mathrm{CaF}_{2}: \mathrm{Tb}$ eutectic composite was obtained after the melt-solidification process. The $\mathrm{LiF} / \mathrm{CaF}_{2}: \mathrm{Tb}$ eutectic composite was able to be easily taken from the carbon crucible. This carbon crucible can be reused due to its low wettability with fluorides. In addition, it was easy to polish the $\mathrm{LiF} / \mathrm{CaF}_{2}: \mathrm{Tb}$ eutectic composite due to its excellent machinability.

Figure 1 shows the prepared $\mathrm{LiF} / \mathrm{CaF}_{2}: \mathrm{Tb}$ eutectic composite illuminated by white LED and $254 \mathrm{~nm}$ UV light source. The size of the prepared sample is approximately $10 \mathrm{~mm}$ diameter and thickness of approximately $2 \mathrm{~mm}$. There are no visible large cracks in the sample. Under UV irradiation, green luminescence was observed from the sample as the PL phenomenon. Because it was not observed in the non-doped $\mathrm{LiF} / \mathrm{CaF}_{2}$ eutectic composite, it is considered to be due to doped $\mathrm{Tb}^{3+}$ ions.

Figure 2 shows the PL emission and excitation spectra of the $\mathrm{LiF} / \mathrm{CaF}_{2}: \mathrm{Tb}$ eutectic composite. The excitation spectrum of the PL emission at $543 \mathrm{~nm}$ shows the excitation band peaking at around $230 \mathrm{~nm}$. In the PL emission spectrum excited at $230 \mathrm{~nm}$, several PL emission peaks are observed in the wavelength range from 380 to $630 \mathrm{~nm}$ that can be the origin of green luminescence under UV irradiation in the visual observation. These peaks can be attributed to $4 \mathrm{f}-4 \mathrm{f}$ transitions of the $\mathrm{Tb}^{3+}$ ion $\left({ }^{5} \mathrm{D}_{3} \rightarrow{ }^{7} \mathrm{~F}_{6}\right.$, ${ }^{5} \mathrm{D}_{3} \rightarrow{ }^{7} \mathrm{~F}_{5}, \quad{ }^{5} \mathrm{D}_{3} \rightarrow{ }^{7} \mathrm{~F}_{4}, \quad{ }^{5} \mathrm{D}_{3} \rightarrow{ }^{7} \mathrm{~F}_{3}, \quad{ }^{5} \mathrm{D}_{3} \rightarrow{ }^{7} \mathrm{~F}_{2}, \quad{ }^{5} \mathrm{D}_{4} \rightarrow{ }^{7} \mathrm{~F}_{6}$ ${ }^{5} \mathrm{D}_{4} \rightarrow{ }^{7} \mathrm{~F}_{5},{ }^{5} \mathrm{D}_{4} \rightarrow{ }^{7} \mathrm{~F}_{4}$, and ${ }^{5} \mathrm{D}_{4} \rightarrow{ }^{7} \mathrm{~F}_{3}$ transitions).

Figure 3 shows the $\mathrm{X}$-ray induced radioluminescence decay curve of the $\mathrm{LiF} / \mathrm{CaF}_{2}: \mathrm{Tb}$ eutectic composite. The obtained decay curve was fitted to a single exponential function and the estimated decay time was $3.69 \mathrm{~ms}$. This value is consistent with the emission from $4 \mathrm{f}-4 \mathrm{f}$ transitions of the $\mathrm{Tb}^{3+}$ ion. At least, the dominant radioluminescence of the $\mathrm{LiF} / \mathrm{CaF}_{2}: \mathrm{Tb}$ eutectic composite is considered to be due to $4 \mathrm{f}-4 \mathrm{f}$ transitions of the $\mathrm{Tb}^{3+}$ ion.

The results of the PL emission spectrum and the X-ray induced radioluminescence decay curve indicate that the

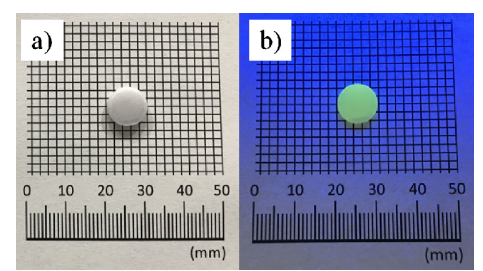

Fig. 1. The $\mathrm{LiF} / \mathrm{CaF}_{2}: \mathrm{Tb}$ eutectic composite illuminated by a) white LED and b) $254 \mathrm{~nm}$ UV light source. 

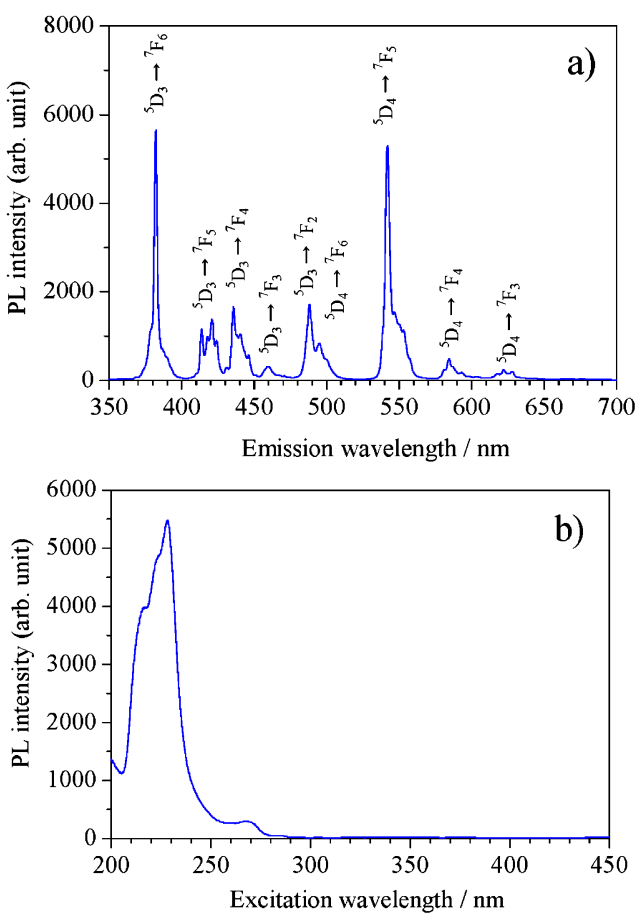

Fig. 2. The PL a) emission spectrum at $230 \mathrm{~nm}$ excitation and b) excitation spectrum at $543 \mathrm{~nm}$ emission of the $\mathrm{LiF} / \mathrm{CaF}_{2}: \mathrm{Tb}$ eutectic composite.

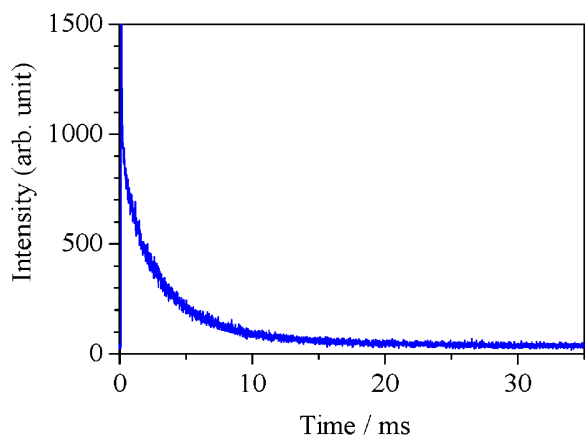

Fig. 3. The X-ray induced radioluminescence decay curve of the $\mathrm{LiF} / \mathrm{CaF}_{2}: \mathrm{Tb}$ eutectic composite.

$\mathrm{LiF} / \mathrm{CaF}_{2}: \mathrm{Tb}$ eutectic composite shows the emission due to $4 \mathrm{f}-4 \mathrm{f}$ transitions of the $\mathrm{Tb}^{3+}$ ion. In the contrast, the non-doped $\mathrm{LiF} / \mathrm{CaF}_{2}$ eutectic composite have shown the emission with self-trapped exciton (STE) in $\mathrm{CaF}_{2}{ }^{22}$ ) It is considered that $\mathrm{Tb}^{3+}$ ions substitute $\mathrm{Ca}^{2+}$ sites and the STE emission is quenched.

The TL emission spectra of the $\mathrm{LiF} / \mathrm{CaF}_{2}: \mathrm{Tb}$ eutectic composite were measured in the temperature range from 50 to $300{ }^{\circ} \mathrm{C}$ after exposure to $1 \mathrm{~Gy}$ of X-rays. We observed emission bands due to $4 \mathrm{f}-4 \mathrm{f}$ transitions of the $\mathrm{Tb}^{3+}$ ion in the temperature range from 50 to $300^{\circ} \mathrm{C}$. Figure 4 shows the selected TL emission spectra at 50, 150, and $250^{\circ} \mathrm{C}$. The $\mathrm{TL}$ emission peaks can be attributed to $4 \mathrm{f}-4 \mathrm{f}$ transitions of the $\mathrm{Tb}^{3+}$ ion $\left({ }^{5} \mathrm{D}_{3} \rightarrow{ }^{7} \mathrm{~F}_{6},{ }^{5} \mathrm{D}_{3} \rightarrow{ }^{7} \mathrm{~F}_{5},{ }^{5} \mathrm{D}_{3} \rightarrow{ }^{7} \mathrm{~F}_{4}\right.$, ${ }^{5} \mathrm{D}_{3} \rightarrow{ }^{7} \mathrm{~F}_{3},{ }^{5} \mathrm{D}_{3} \rightarrow{ }^{7} \mathrm{~F}_{2},{ }^{5} \mathrm{D}_{4} \rightarrow{ }^{7} \mathrm{~F}_{6},{ }^{5} \mathrm{D}_{4} \rightarrow{ }^{7} \mathrm{~F}_{5},{ }^{5} \mathrm{D}_{4} \rightarrow{ }^{7} \mathrm{~F}_{4}$, and ${ }^{5} \mathrm{D}_{4} \rightarrow{ }^{7} \mathrm{~F}_{3}$ transitions), as is the case for the PL emission spectrum. Emission peaks had no change depending on the stimulation temperature.

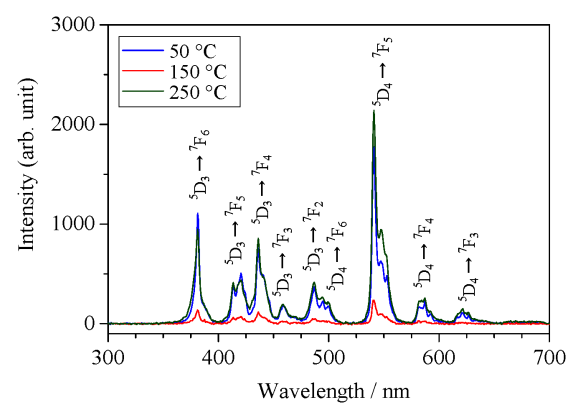

Fig. 4. TL emission spectra of the $\mathrm{LiF} / \mathrm{CaF}_{2}$ :Tb eutectic composite at 50,150 , and $250^{\circ} \mathrm{C}$ after exposure to $1 \mathrm{~Gy}$ of X-rays.

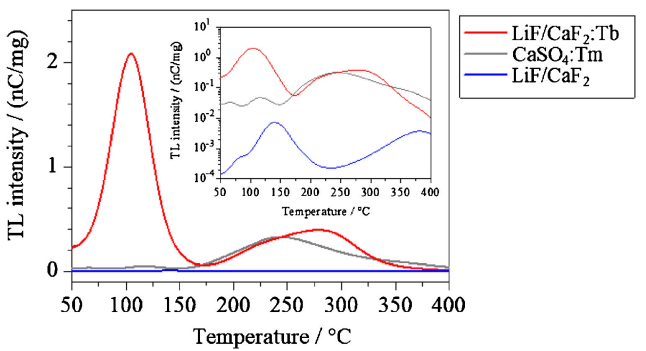

Fig. 5. TL glow curves of $\mathrm{LiF} / \mathrm{CaF}_{2}: \mathrm{Tb}, \mathrm{CaSO}_{4}$ :Tm, and nondoped $\mathrm{LiF} / \mathrm{CaF}_{2}$ after exposure to $10 \mathrm{mGy}$ of $\mathrm{X}$-ray. The inset graph has a logarithmic scale on the vertical axis.

Figure 5 shows the TL glow curves of $\mathrm{LiF} / \mathrm{CaF}_{2}: \mathrm{Tb}$, $\mathrm{CaSO}_{4}: \mathrm{Tm}$, and non-doped $\mathrm{LiF} / \mathrm{CaF}_{2}$ after exposure to $10 \mathrm{mGy}$ of X-ray. Between each measurement, TL glow curves using no samples were measured for background subtraction. Furthermore, the TL intensity on the vertical axis was corrected by the sample weight. While the TL intensities of $\mathrm{LiF} / \mathrm{CaF}_{2}: \mathrm{Tb}$ and $\mathrm{CaSO}_{4}: \mathrm{Tm}$ are comparable, that of non-doped $\mathrm{LiF} / \mathrm{CaF}_{2}$ is significantly lower. Broad TL glow peaks of $\mathrm{LiF} / \mathrm{CaF}_{2}: \mathrm{Tb}$ are observed at around 100,250 , and $300^{\circ} \mathrm{C}$. In non-doped $\mathrm{LiF} / \mathrm{CaF}_{2}, \mathrm{TL}$ glow peaks at 250 and $300^{\circ} \mathrm{C}$ are not observed. In general, a glow peak temperature is related to a trap depth. It is possible that trapping centers corresponding to these peaks are induced by $\mathrm{Tb}$-doping.

Table 1 shows integrated TL intensities of $\mathrm{LiF} / \mathrm{CaF}_{2}$ : $\mathrm{Tb}$, non-doped $\mathrm{LiF} / \mathrm{CaF}_{2}$, and $\mathrm{CaSO}_{4}: \mathrm{Tm}$ in the temperature range from 100 to $300^{\circ} \mathrm{C}$ after exposure to $10 \mathrm{mGy}$ of X-ray. The integrated TL intensity of the $\mathrm{LiF} / \mathrm{CaF}_{2}: \mathrm{Tb}$ eutectic composite is 3.6 times higher than that of the commercial $\mathrm{CaSO}_{4}: \mathrm{Tm}$ dosimetric material. In addition, comparing with non-doped $\mathrm{LiF} / \mathrm{CaF}_{2}$, it is confirmed that Tb-doping drastically increase the TL intensity.

Figure 6 shows the dose response curve of the $\mathrm{LiF} /$ $\mathrm{CaF}_{2}: \mathrm{Tb}$ eutectic composite. The value for vertical axis is the integrated TL intensity $\left(I_{\mathrm{TL}}\right)$ in the temperature range from 100 to $300{ }^{\circ} \mathrm{C}$. The $I_{\mathrm{TL}}$ of the $\mathrm{LiF} / \mathrm{CaF}_{2}: \mathrm{Tb}$ eutectic composite monotonically increases increasing with $\mathrm{X}$-ray dose $(D)$ from 0.01 to $10 \mathrm{mGy}$. The lower detection limit is $0.01 \mathrm{mGy}$. Table 2 summarize the lower detection limits of $\mathrm{LiF} / \mathrm{CaF}_{2}: \mathrm{Ce}, \mathrm{LiF} / \mathrm{CaF}_{2}: \mathrm{Eu}$, non-doped $\mathrm{LiF} / \mathrm{CaF}_{2}$, and $\mathrm{LiF} / \mathrm{CaF}_{2}: \mathrm{Tb}$. In the table, the $\mathrm{LiF} / \mathrm{CaF}_{2}: \mathrm{Tb}$ eutectic composite shows the lowest value among the $\mathrm{LiF} / \mathrm{CaF}_{2}$ based composites. It is due to its high TL intensity which is 3.6 
Table 1. Integrated $\mathrm{TL}$ intensities of $\mathrm{LiF} / \mathrm{CaF}_{2}: \mathrm{Tb}$, non-doped $\mathrm{LiF} / \mathrm{CaF}_{2}$, and $\mathrm{CaSO}_{4}: \mathrm{Tm}$ after exposure to $10 \mathrm{mGy}$ of $\mathrm{X}$-ray

\begin{tabular}{ccc}
\hline & $\begin{array}{c}\text { TL intensities } \\
(\mathrm{nC} / \mathrm{mg})\end{array}$ & $\begin{array}{c}\text { Relative TL } \\
\text { intensities }\end{array}$ \\
\hline $\mathrm{LiF} / \mathrm{CaF}_{2}: \mathrm{Tb}$ & 158 & 3.6 \\
non-doped $\mathrm{LiF} / \mathrm{CaF}_{2}$ & 0.57 & 0.013 \\
$\mathrm{CaSO}_{4}: \mathrm{Tm}$ & 44 & 1 \\
\hline
\end{tabular}

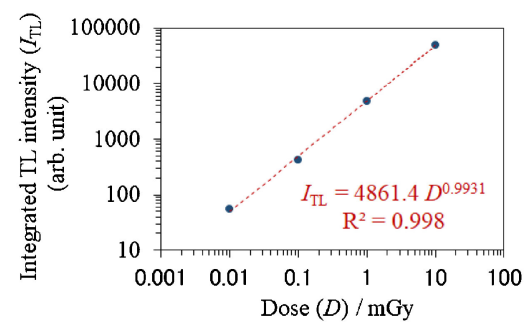

Fig. 6. The dose response curve of the $\mathrm{LiF} / \mathrm{CaF}_{2}: \mathrm{Tb}$ eutectic composite.

Table 2. Lower detection limits of $\mathrm{LiF} / \mathrm{CaF}_{2}: \mathrm{Ce}, \mathrm{LiF} / \mathrm{CaF}_{2}: \mathrm{Eu}$, non-doped $\mathrm{LiF} / \mathrm{CaF}_{2}$, and $\mathrm{LiF} / \mathrm{CaF}_{2}: \mathrm{Tb}$

\begin{tabular}{ccc}
\hline & $\begin{array}{c}\text { Lower detection limits } \\
(\mathrm{mGy})\end{array}$ & References \\
\hline $\mathrm{LiF} / \mathrm{CaF}_{2}: \mathrm{Ce}$ & $0.1-1$ & $20)$ \\
$\mathrm{LiF} / \mathrm{CaF}_{2}: \mathrm{Eu}$ & 1 & $21)$ \\
non-doped $\mathrm{LiF} / \mathrm{CaF}_{2}$ & 0.1 & $22)$ \\
$\mathrm{LiF} / \mathrm{CaF}_{2}: \mathrm{Tb}$ & 0.01 & This work \\
\hline
\end{tabular}

times higher than that of the commercial $\mathrm{CaSO}_{4}$ : $\mathrm{Tm}$ dosimetric material after exposure to $10 \mathrm{mGy}$ of $\mathrm{X}$-ray.

\section{Conclusions}

The $\mathrm{LiF} / \mathrm{CaF}_{2}: \mathrm{Tb}$ eutectic composite was obtained by the melt-solidification method. In the PL emission and excitation spectra, the X-ray induced radioluminescence decay curve, and the TL emission spectrum, we confirmed luminescence properties that are considered to be due to $4 \mathrm{f}-4 \mathrm{f}$ transitions of the $\mathrm{Tb}^{3+}$ ion. The integrated TL intensity of the $\mathrm{LiF} / \mathrm{CaF}_{2}: \mathrm{Tb}$ eutectic composite was 3.6 times higher than that of the commercial $\mathrm{CaSO}_{4}: \mathrm{Tm}$ dosimetric material. From the dose response curve, it was confirmed that the lower detection limit is $0.01 \mathrm{mGy}$. The $\mathrm{LiF} / \mathrm{CaF}_{2}$ : $\mathrm{Tb}$ eutectic composite showed the lowest detection limit among the $\mathrm{LiF} / \mathrm{CaF}_{2}$ based composites.

Acknowledgements This work was supported by Grants-in-Aid for Scientific Research A (17H01375), B (18H03468 and 19H03533), and Early-Career Scientists (20K20104) from Japan Society for the Promotion of Science. The Cooperative Research Project of the Research Center for Biomedical Engineering, Iketani Science and Technology Foundation, and Nippon Sheet Glass Foundation are also acknowledged.

\section{References}

1) J. Llorca and V. M. Orera, Prog. Mater. Sci., 51, 711809 (2006).
2) V. M. Orera, J. I. Peña, R. I. Merino and A. Larrea, J. Cryst. Growth, 360, 99-104 (2012).

3) M. Yoshimura, S. Sakata, H. Iba, T. Kawano and K. Hoshikawa, J. Cryst. Growth, 416, 100-105 (2015).

4) Y. Waku, H. Ohtsubo, N. Nakagawa and Y. Kohtoku, J. Mater. Sci., 31, 4663-4670 (1996).

5) C. W. E. van Eijk, Nucl. Instrum. Meth. A, 460, 1-14 (2001).

6) T. Yanagida, Opt. Mater., 35, 1987-1992 (2013).

7) S. E. Derenzo, M. J. Weber, E. Bourret-Courchesne and M. K. Klintenberg, Nucl. Instrum. Meth. A, 505, 111117 (2003).

8) G. F. Knoll, "Radiation Detection and Measurement", Wiley, New York (2010).

9) N. Kawaguchi, K. Fukuda, T. Yanagida, Y. Fujimoto, Y. Yokota, T. Suyama, K. Watanabe, A. Yamazaki and A. Yoshikawa, Nucl. Instrum. Meth. A, 652, 209-211 (2011).

10) H. Masai, T. Yanagida, T. Mizoguchi, T. Ina, T. Miyazaki, N. Kawaguchi and K. Fukuda, Sci. Rep., 5, 13332 (2015).

11) N. Kawaguchi, G. Okada, K. Fukuda and T. Yanagida, Nucl. Instrum. Meth. A, 954, 161518 (2020).

12) S. W. S. McKeever, "Thermoluminescence of Solids", Cambridge University Press, Cambridge (1985).

13) S. W. S. McKeever, Nucl. Instrum. Meth. B, 184, 29-54 (2001).

14) E. G. Yukihara and S. W. S. McKeever, "Optically Stimulated Luminescence", Wiley, Chichester, UK (2011).

15) S. W. S. McKeever, Radiat. Meas., 46, 1336-1341 (2011).

16) Y. Miyamoto, T. Yamamoto, K. Kinoshita, S. Koyama, Y. Takei, H. Nanto, Y. Shimotsuma, M. Sakakura, K. Miura and K. Hirao, Radiat. Meas., 45, 546-549 (2010).

17) Y. Miyamoto, Y. Takei, H. Nanto, T. Kurobori, A. Konnai, T. Yanagida, A. Yoshikawa, Y. Shimotsuma, M. Sakakura, K. Miura, K. Hirao, Y. Nagashima and T. Yamamoto, Radiat. Meas., 46, 1480-1483 (2011).

18) H. Nanto, Y. Miyamoto, T. Oono, Y. Takei, T. Kurobori and T. Yamamoto, Procedia Engineer., 25, 231-234 (2011).

19) B. C. Bhatt, Radiat. Prot. Environ., 34, 6-16 (2011).

20) N. Kawano, N. Kawaguchi, K. Fukuda, G. Okada and T. Yanagida, Opt. Mater., 82, 60-64 (2018).

21) N. Kawano, N. Kawaguchi, K. Fukuda, G. Okada and T. Yanagida, J. Mater. Sci.-Mater. El., 29, 8964-8969 (2018).

22) N. Kawaguchi, H. Kimura, Y. Takebuchi, D. Nakauchi, T. Kato and T. Yanagida, Radiat. Meas., 132, 106254 (2020).

23) N. Kawaguchi, D. Nakauchi, S. Hirano, N. Kawano, G. Okada, K. Fukuda and T. Yanagida, Jpn. J. Appl. Phys., 57, 02CB13 (2018).

24) T. Yanagida, Y. Fujimoto, T. Ito, K. Uchiyama and K. Mori, Appl. Phys. Express, 7, 062401 (2014).

25) G. Okada, T. Kato, D. Nakauchi, K. Fukuda and T. Yanagida, Sensor. Mater., 8, 897-904 (2016).

26) T. Yanagida, Y. Fujimoto, N. Kawaguchi and S. Yanagida, J. Ceram. Soc. Jpn., 121, 989-991 (2013). 